\title{
Motivation and Criteria in Accepting New Music Talents on YouTube
}

\author{
[Mohd Syuhaidi Abu Bakar, Shereen Nadira Jasney]
}

\begin{abstract}
This quantitative study explored motivation of the public to use YouTube; and the elements of criteria, which the public are looking for to accept new talents on the UserGenerated Content (UGC) sites. There are mass inputs on the net but the publics are still being very selective in accepting new talents. Thus, it is important to identify determinant factors that contribute to the acceptance of new talents on YouTube so it can be exemplary on other UGC sites. Due to time constraint, a total number of 236 respondents $(\mathbf{n}=\mathbf{2 3 6})$ have participated in this study using Simple Random Sampling. Data was collected using Google Forms and was analyzed with Descriptive Analysis. The findings of this paper advocate that tremendous expansion; and diversification offered by YouTube are among main factors that motivated public viewers in using YouTube on accepting new talents. It was also found that by being relatable and concurrently providing interesting contents, having the artist name and song title in the YouTube talent's title video and also the number of views and likes of the video are some of the criteria that the public are looking for in accepting new talents on the UGC sites. This paper introduces YouTube as a mean of discovering new talents in the music industry where the public, especially the younger generations, whom are actively engaged with current digital landscape that they've been presently silverplated.
\end{abstract}

Keywords-Motivation, Criteria, New Talents, UGC, YouTube

\section{Introduction}

The invention of the Internet is like the new way of communication environment among the people today as it offers many kinds of opportunities and challenges in every aspect. The proper way of using the Internet has also become a key source of productivity and competitiveness for all kind of business [4]. The 13-24 year olds are watching more online digital content rather than television [16]. There are many online videos sharing web sites that offer various kinds of contents according to every individual need and interest. One of the most famous video sharing sites is YouTube and the reason of its popularity is because of its high acceptance among users. YouTube is one of User Generated Content (UGC) sites encompassed of text, audio, cinematographic, and phantasmagorias $[10,18]$.

\section{Problem Statement}

UGC sites begun to gain acceptance and popularity by permitting users to distribute text, audio, video, and images they have created posted on content sharing sites (e.g. YouTube, Slashdot). Other sharing sites were social networking sites (e.g. Facebook), blogs (e.g. Blogger.com, Wordpress), and other online media platform $[1,2,11]$. The consumption and demands of online videos at that moment was swiftly increasing, along with the extensive insertion of video competence in digital cameras and mobile phones $[2,10,15]$. Young generations today are more interested and attracted to look for new talents online via the Internet through the many popular video-sharing sites such as YouTube. Justin Bieber, Greyson Chance, local acts like Najwa Latiff, Zee Avi and Yuna are able to gain the public interest and kick started their career journey from there [5]. However, no study has yet tapped into elements that motivate the viewers to use YouTube as an access to these limitless new talents and the criteria of viewers are looking for to accept new music talents on the UGC sites. Thus, this study intends to identify the motivation and criteria in accepting new music talents on YouTube.

\section{Methodology}

A quantitative study using Google Forms was done with a number of 236 respondents participating in the online survey using Google Forms. All YouTube users in Malaysia were included in this research, for two reasons. First, the collection of data for all the populations was hands-on and money-wise feasible. Second, the requirement about the sample size by chosen analysis techniques; Descriptive Analysis, requires a considerable sample size in order to get reliable estimates. One way of setting a sample number is by referring to a sampling table. The determinant sample size for this study was based on the Krejie and Morgan sampling table. $5.14 \%$ out of 28,552,712 citizens of Malaysia used YouTube for various purposes in the stipulated year [13]. This figure has eased the sampling determinacy for this study. Thus $n=400$ was determined for this study. Due to time constraint, 236 respondents managed to participate in the online survey and all of the participation is accepted as there were no indication of incomplete answers. A researcher suggested that samples larger than 30 and less than 500 are suitable for most research [14]. All 30 items in this study were extracted from studies of $[6,12,16,17,19]$ with the level of minimum reliability established in the 0.70 to 0.80 range.

As stated above, this study uses online survey questionnaires via Google Forms to collect its data. Google Forms is a freeware web-based office suite offered by Google within its Google Drive service, which saves documents on the Internet. Many scholars have recently adopted Google Forms as a means of completing online surveys as it keeps data safe in the most basic format of spreadsheets. Scholars can later transfer the data and do all of the calculations in the SPSS program. This free software becomes the mediator for professional level statistics program. There are many rewards in using online survey. One of them is the luxury of entry to individuals from distant whereabouts [3] and extra power to reach contributors who are hard to communicate, and automated 
data collection is convenience to the researcher. This decreases labor and time [20]. In addition, the mistakes of coding data from paper to electronic file can be condensed. This is because data can easily be transported from the Google Form database into SPSS file for analysis. Also, these testimonials are also supported by past online surveys, such as simpler approach to a wider range of consumers, low budget, and power to capture the analyzed data quickly. These features make an online survey fit for cross-national research [7]. As 30 items were used in this study, findings are discussed based on importance and most significant numbers of percentages.

\section{Findings}

\section{A. Respondents Characteristic}

In this study, 236 respondents managed to participate with $0 \%$ of unusable responds. Out of this number, $26.7 \%$ are male respondents and the other $73.3 \%$ were female respondents. Majority of the respondents are Malay (81\%) with $11.4 \%$ of the respondents are Chinese and the other $2.5 \%$ are Indian ethnic groups, whilst the rest represented other ethnic groups. The majority of the respondents are students $(78.4 \%)$. The remaining users were employed and unemployed respondents, $14 \%$ and $7.6 \%$ respectively.

\section{B. Motivation in Accepting New Music Talents on YouTube}

$51.9 \%$ of the respondents chooses YouTube to access to limitless new talents due to technological based service provided by YouTube (i.e the ability to use YouTube on their smartphones). With this, respondents are able to spend more time on UGC sites. $45.3 \%$ of them spent more than 4 hours a day on the Internet alone thus providing them ample time to appreciate the talent provided. $51.9 \%$ of them agreed that YouTube is the most efficient and cost saving medium in discovering new music talents in the entertainment industry, and only $8.5 \%$ of the respondents say that they discover new music talents through gigs, shows, and festival. $32.2 \%$ of the respondents say they discover new music talents several times a month on YouTube; and majority of the respondents, which is $60.6 \%$, says that they do not actively search for new music talents but where suggested by the UGC through the medium of email. Thus, they have been accustomed to use YouTube for music seeking purposes. $53.4 \%$ of the respondents admitted to this. Respondents seemed to choose the music genre of pop and $\mathrm{R} \& \mathrm{~B}$ as their popular choice, which stands at $31.7 \%$ and $25.6 \%$ respectively; and $56.4 \%$ of the respondents has previously shared the videos they have watched to other social media network, creating a bigger, viral situation these talents. Thus, no wonder that the most frequent types of video categories in which the respondents always visited was the music and entertainment categories, which is $37.7 \%$ and $33.3 \%$ respectively. The lifestyle category came in second with $13.2 \%$. About $4.9 \%$ of the respondents look into the gadgets and games section and the remaining $6.6 \%$ chose all of the categories above. The remaining $4.2 \%$ chose different other categories such as sports, documentary, motorcars, tutorials and martial arts.

\section{Criteria in Accepting New Music Talents on YouTube}

One of the most important criteria which the respondents are looking for when they are searching for new videos or music talents on YouTube was the availability of a perfect description of the video, that encompasses of the artist name itself and the songs title, which stands at $40.2 \%$. The next popular choice is between the ratings and recommendation from others, as well as the number of views and likes which stands at $21.4 \%$ and $21.10 \%$ each. A $55.5 \%$ or 131 respondents prefer to watch only nonemainstreamed YouTube music talents, however $67.8 \%$ of the respondents' states that the opportunity given by YouTube to both of YouTube talents and record label artist made them choose the UGC for such niche purposes. They also agreed that the quality of YouTube talents and record label artist were equal. $34.4 \%$ of the respondents stated that the artist' name and song titles are the main criteria they look for in subscribing to channels of music talent on YouTube. $25.5 \%$ of respondents looked at the number of views and likes. $16.8 \%$ of the respondents look at the professionally produce content and $9.2 \%$ are motivated by the ratings of the channel. About $8.9 \%$ are motivated by the number of subscribers and the remaining of $5.2 \%$ chose other reasons such as the interesting, funny or fun video contents, personal likings and the overall quality of the video

\section{Conclusion}

The findings of this study have proven that users motivation to construct content online and strategies producing Internet content, psychological enablement and civic arrangement affect Internet content-generation activities are imperative research topics. Building on the findings, it can be concluded that there is a lot of opportunity for scholars to undertake research, which contributes drastically to the growth of research in the area of curating online contents.

\section{Acknowledgment}

I would like to thank the Dean of Faculty of Film, Theatre and Animation (FiTA), UiTM Selangor, Puncak Perdana Campus; Dato' Prof A. Razak Hj Mohaideen; Deputy Dean (Academic), Dr Wan Aida Wan Yahya; Head of Centre (Artistic Writing), Encik Ibrahim Jamaluddin; Head of Postgraduate Studies, Dr Norman Yusoff; and Prof Dr Solehah Ishak who have always supported, encouraged and believed in my interest towards research writing. I also take this opportunity to express a deep sense of gratitude to the management of FiTA that has agreed to fund the presentation of this research paper; and Shereen that has succcesfully, under my supervision, written an undergraduate thesis on this area of study. I dedicate this research paper to my parents, Tuan Haji Abu Bakar Daud and Puan Hajjah Fatimah Mat Hassan for their continuous love and their supports in my decisions. Without whom I could not have made it here.

\section{References}

[1] Bakshy, E., Karrer, B., \& Adamic, L. A. Social influence and the diffusion of user-created content. In Proceedings of the 10th ACM 
conference on Electronic commerce ACM (2009) 325-334

[2] Bernoff, J., \& Li, C. Harnessing the power of the oh-so-social web.MIT Sloan management review, 49(3) (2008) 36.

[3] Bryman, A., and E. Bell. "Business research strategies." Business research methods (2007).

[4] Castells, M. The internet galaxy: Reflections on the internet, business, and society. Oxford, USA: Oxford University Press (2001).

[5] CNN. Youtube leads to fame for singing sensation. Retrieved May 4, 2014, from http://edition.cnn.com/2009/SHOWBIZ/Music/06/02/zee.avi/ (2009, June)

[6] Dillman, D. A. Mail and internet surveys: The tailored design method(Vol. 2). New York: Wiley (2000)

[7] Gerardi, Robert. Opportunities in music careers. McGraw Hill Professional (2002).

[8] Jordão, Aida. "Inês de Castro on YouTube: Re-gendered Narratives." In Proceedings of the Interactive Narratives, New Media \& Social Engagement International Conference. Eds. Hudson Moura, Ricardo Sternberg, Regina Cunha, Cecília Queiroz, and Martin Zeilinger (2014) ISBN: 978-0-9939520-0-5.

[9] Kim, A. J., \& Ko, E. Impacts of luxury fashion brand's social media marketing on customer relationship and purchase intention. Journal of Global Fashion Marketing, 1(3) (2010) 164-171.

[10] Lai, L. S., \& Turban, E. Groups formation and operations in the Web 2.0 environment and social networks. Group Decision and Negotiation, 17(5) (2008) 387-402.

[11] Miller, L. S. We asked the experts: How do you do youtube? Retrieved from https://gigaom.com/2013/03/04/youtube-usage-survey/ (2013, March 4)

[12] Mustaffa, N., Ibrahim, F., Mahmud, W. A. W., Ahmad, F., Kee, C. P., \& Mahbob, M. H. Diffusion of Innovations: The Adoption of Facebook among Youth in Malaysia. The Public Sector Innovation Journal, 16(3) (2011) 1-15.

[13] Roscoe, J. T. Fundamental research statistics for the behavioral sciences [by] John T. Roscoe. Holt, Rinehart and Winston, New York, NY (1975)

[14] Ryu, M. H., Kim, S., \& Lee, E. Understanding the factors affecting online elderly user's participation in video UCC services. Computers in Human Behavior, 25(3) (2009) 619-632.

[15] Smith, A. 13-24 year olds are watching more YouTube than TV. Retrieved from http://www.reelseo.com/13-24-watching-more-youtube-than-tv/ (2015, March 11).

[16] Sysomos. A look inside online video engagement: Part I an in-depth look at the use of online video sharing sites within blogs. Retrieved from https://www.sysomos.com/reports/video (2009, October)

[17] Valcke, P., \& Lenaerts, M. Who's author, editor and publisher in usergenerated content? Applying traditional media concepts to UGC providers. International Review of Law, Computers \& Technology 24(1) (2010) 119-131.

[18] Venturini, F. (2012). Accenture video over internet consumer survey 2012. Retrieved from http://www.accenture.com/SitCollectionDocuments/PDF/AcentureVideo-OverInternet-Consumer-Survey-2012.pdf

[19] Wright, C. C.. The kappa statistic in reliability studies: use, interpretation, and sample size requirements. Physical therapy, 85(3) (2005) 257-268.

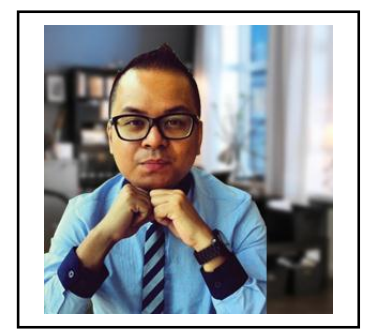

Mohd Syuhaidi Abu Bakar is a lecturer in the Creative Writing Programme, Faculty of Film, Theatre, \& Animation (FiTA), Universiti Teknologi MARA (Malaysia) 